\title{
Evaluating efficiency and stability of calcite scaling inhibitors at high pressure and high temperature in laboratory scale
}

\author{
Joerg Zotzmann ${ }^{*}$, , Alexandra Vetter and Simona Regenspurg
}

${ }^{*}$ Correspondence: 1joerg.zotzmann@gfz-potsdam.de Helmholtz Centre Potsdam, German Research Centre for Geosciences (GFZ), Telegrafenberg, 14473 Potsdam, Germany

\begin{abstract}
Reduction or prevention of scaling is commonly achieved by injecting scaling inhibitors into the geothermal circuit. Inhibitor-efficiency tests can be carried out in static or dynamic experiment set-ups allowing measurements at high pressures and high temperatures (HPHT). For these measurements, suitable analytical methods have to be selected depending on the nature of the scales and the specifics of the related sensors in a HPHT environment. In this study, a calcite scaling inhibitor was evaluated in static batch tests at HPHT conditions with respect to its inhibitory efficiency as well as its degradation behaviour. The inhibitor efficiency significantly decreases in comparison to ambient p,T-conditions. In a long-term stability experiment, a delayed partial degradation of the inhibitor at HPHT conditions could be observed.
\end{abstract}

Keywords: Geothermal fluid, Calcite scaling, Inhibitor efficiency, High-pressure hightemperature conditions

\section{Background}

Temperature and pressure changes during production of geothermal fluids can lead to oversaturation of dissolved minerals and thus to mineral precipitation. Scaling can severely damage geothermal installations or decrease the injectivity of the reservoir (Gallup 2009; Regenspurg et al. 2010; Tomaszewska and Pająk 2012; Wanner et al. 2017; Boch et al. 2017). Over many years, scale inhibitors have been applied to overcome this problem. Such inhibitors have been developed for application in oil field production, water heating facilities, industrial waste water disposal, and circulating cooling systems, effectively preventing the formation of mineral scales such as calcite or barite (Amro 2005; Graham et al. 2003; Collins et al. 2004; Sullivan et al. 1996; Choi et al. 2002). However, when applied in geothermal installations, the effectivity of these commonly used inhibitors can decrease considerably due to the special physico-chemical conditions of geothermal fluids such as high pressure, high temperature, high salinity or content of corrosive or scale-forming chemicals. These conditions have to be taken into account when the efficiency of scaling inhibitors for geothermal application is tested. Furthermore, established scaling inhibitors based on phosphates or phosphonates are known to have toxic effects on aquatic organisms or cause eutrophication problems (Hasson et al. 2011; Lattemann and Höpner 2008). Based on their chemical composition, some

(c) The Author(s) 2018. This article is distributed under the terms of the Creative Commons Attribution 4.0 International License (http://creativecommons.org/licenses/by/4.0/), which permits unrestricted use, distribution, and reproduction in any medium, provided you give appropriate credit to the original author(s) and the source, provide a link to the Creative Commons license, and indicate if changes were made. 
inhibitors are expected to be persistent or even cumulative in the reservoir. Environmental concerns of the governmental authorities are increasing and enforce the usage of "green" inhibitors that are non-toxic and biodegradable (Chaussemier et al. 2015; Popov et al. 2016). New scaling inhibitors meeting these requirements were lately tested with regard to their inhibitory efficiency (Reddy and Hoch 2001; Baraka-Lokmane et al. 2008; Kavitha et al. 2011; Choi et al. 2002) but scarcely at elevated temperatures such as occurring in geothermal fluids (Topçu et al. 2017; Ketrane et al. 2009).

Before investigating the effectivity of a potentially scaling-inhibiting substance, its compatibility to the geothermal fluid needs to be tested. Most scaling inhibitors are water-soluble polymers that can be diluted in water at any desired ratio. In geothermal fluids of high salinity, however, the solubility of these polymers can be compromised. A diluting test in the geothermal fluid (natural or artificial with comparable ionic strength) will determine the compatibility of the inhibitor to the fluid.

A variety of analytical methods can be applied in order to evaluate inhibitor efficiency by measuring changes in the physico-chemical properties of the fluid during the scaling process. In laboratory scale, two kinds of tests are used with different set-ups. The most widely used jar or bottle test is carried out in a reactor at static conditions. The test set-up is easily assembled by using a container where a fluid batch is mixed with the inhibitor and monitored until the equilibrium is reached (static batch test). In static batch tests, the extent of scaling can be quantified by measuring the change of a broad variety of measurable fluid properties such as the $\mathrm{pH}$ value, the electrical conductivity, the concentration of certain ions, or the amount of solid precipitation. Depending on the reaction conditions and the used sensors, these parameters can be monitored on-line during the experiment or measured off-line after termination of the experiment. The static batch test is mostly carried out under ambient conditions or moderately elevated temperatures at atmospheric pressure. These conditions resemble those of water heating facilities, industrial waste water disposal, and circulating cooling systems. However, for geothermal purposes, the inhibitor will encounter reservoir conditions, which are characterized by high pressure and high temperature (HPHT). Particularly, the temperature influences the performance of inhibitors since mineral saturation and most of the relevant chemical equilibria are strongly temperature-dependent. The inhibitory effect of geothermal scaling inhibitors therefore has to be determined under HPHT conditions (Sorbie and Laing 2004; Inches et al. 2007) and reactors as well as analytical sensors are needed that allow measurement under these extreme conditions.

In contrast to the static batch test, the tube blocking test is carried out under dynamic conditions by pumping continuously freshly mixed fluid through a tube (Bazin et al. 2005) where HPHT conditions can be adjusted. Quantification of the precipitation is realized by measuring the differential pressure over the tube. Both tests enable the quantification of the inhibitory effect by measuring the scaling related change of a physical or chemical quantity over a certain time. The inhibitor effectivity can be transformed into an efficiency by relating it to the amount of inhibitor necessary for the effect. Ranking of scaling inhibitors is realized by comparing the minimum inhibitor concentration (MIC), which is defined as the concentration of inhibitor required to obtain an inhibitory effect of predefined extent (Graham et al. 2006). Applying a given test procedure, the lower the MIC for a scaling inhibitor, the 
higher is the inhibition performance. However, different and sometimes contradictory ranking orders of scaling inhibitors were obtained when different effectivity test methods were applied (Bazin et al. 2005; Popov et al. 2016).

Due to high temperatures in geothermal fluids above ground as well as in the reservoir, scaling inhibitors might also be subject to thermal decomposition. Thermal stability of scaling inhibitors plays a crucial role in geothermal applications. It has to be guaranteed over a certain timeframe until the inhibitor-containing fluid in the reservoir has distributed away from the injection bore hole far enough that the fluid comes close to the reservoir equilibrium and failing of the inhibitory capability does not lead to scaling and injectivity reduction any more. However, since the chemical behaviour of inhibitors in the reservoir over long time periods is mostly unknown, a delayed degradation of the inhibitors is intended to avoid their persistence or accumulation in the reservoir. Besides non-toxicity, this is a characteristic feature of "green" inhibitors (Chaussemier et al. 2015).

In this study, we investigated calcite inhibitors based on polycarboxylates with regard to their potential for geothermal application. These inhibitors were originally developed for preventing calcite scaling in industrial wastewater. Belonging to the antiscalant class of polyelectrolytes, polycarboxylates (see Fig. 1) are postulated to deploy the "threshold mechanism". In contrast to complexation that disables the metal ions from forming crystals at all, the polyelectrolytes are postulated to adhere to the surface of microcrystals and occupy the active centres of crystal growth (see Fig. 2, Cooper et al. 1979; Reddy and Hoch 2001; Ketrane et al. 2009). The microcrystals are prevented from further growing and do not precipitate. However, by the formation of calcite microcrystals, the concentration of calcite in solution is reduced until it is undersaturated. Threshold inhibitors are of economic interest since they can be used in under-stoichiometric quantities in contrast to complexing reagents.

Following a compatibility test for highly saline fluids on three different inhibitors, a static batch test system was established and evaluated applying one inhibitor to a synthetic substitute of a calcium-rich geothermal fluid. Several analytical methods were tested and their potential to quantify the inhibitory effect evaluated. The MIC of the tested inhibitor was determined at HPHT conditions and compared with the MIC at ambient conditions. The intention of these experiments was to ascertain the difference in MIC under HPHT conditions from ambient conditions. The thermal stability of the inhibitor was investigated by conducting a long-term experiment under HPHT conditions.

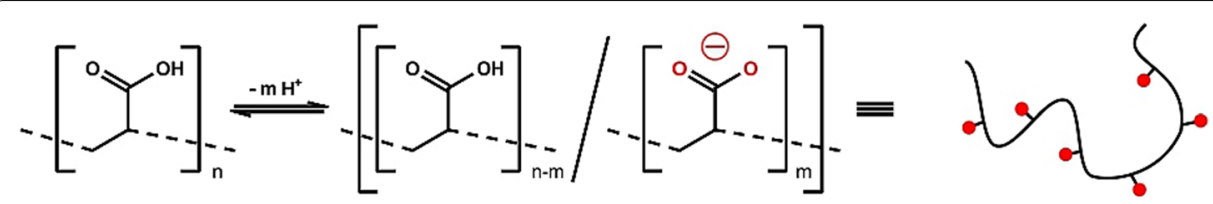

Fig. 1 Partial deprotonation of a polycarboxylic acid to form a polyelectrolyte, red: electric charge carrying carboxylate groups 


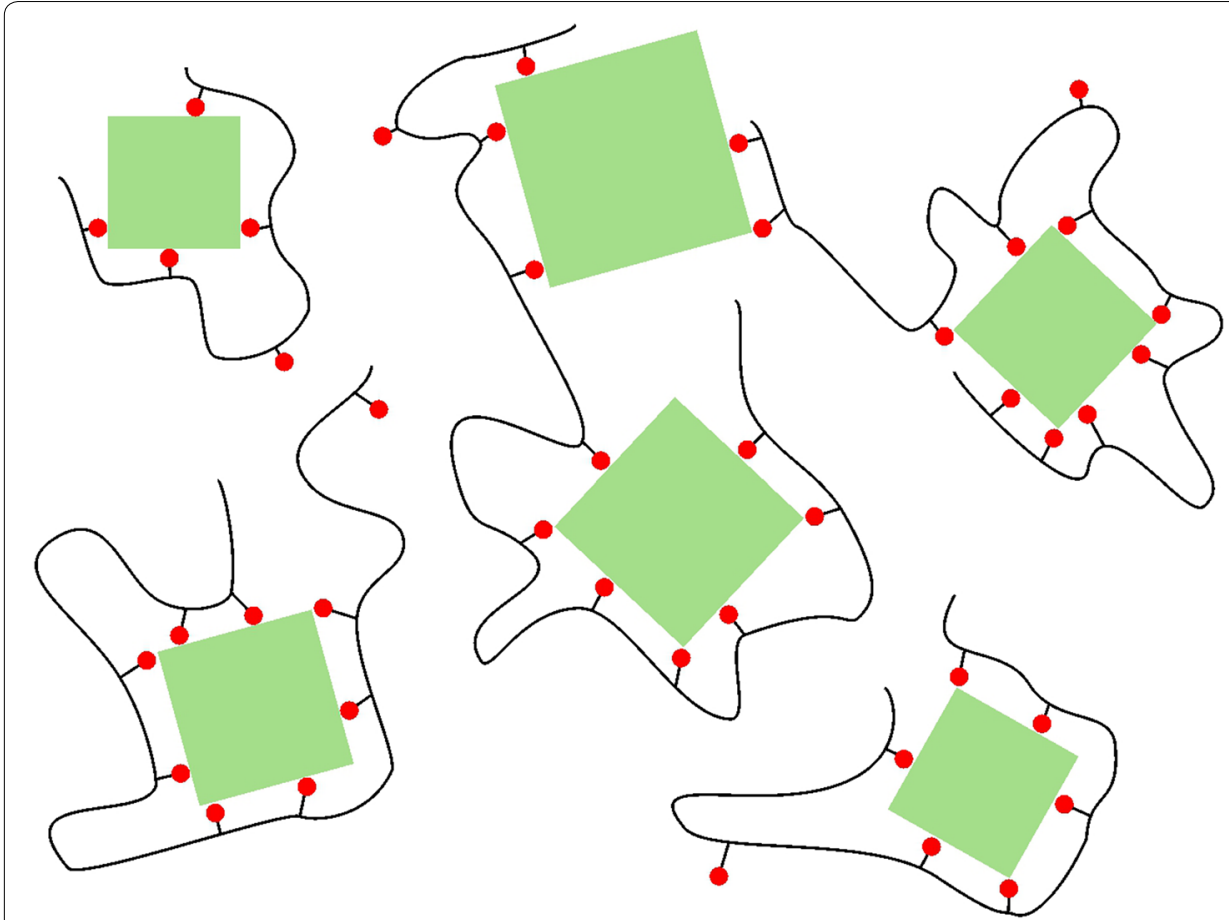

Fig. 2 Illustration of scaling inhibition by the postulated threshold mechanism, green: $\mathrm{CaCO}_{3}$-microcrystals, red: carboxylate groups, black: polymer backbone

\section{Methods}

A stainless steel laboratory autoclave $(250 \mathrm{~mL}$ reaction chamber with Teflon insertion) equipped with a heater/stirrer and temperature control unit (Berghof GmbH, Eningen, Germany) was applied as batch reactor for the inhibitor effectivity measurements. HPHT probes such as a temperature sensor, an antimony solid phase $\mathrm{pH}$ electrode, a four-electrode electrical conductivity sensor (both sensors Kurt Schwabe Institut, Meinsberg, Germany) and a sonic velocity sensor (LiquiSonic, SensoTech $\mathrm{GmbH}$, Magdeburg, Germany) were applied. All electrodes were designed to fit into the autoclave and to enable measurements under conditions up to a pressure of $150 \mathrm{bar}$ and a temperature of $125-200{ }^{\circ} \mathrm{C}$, respectively. A schematic of the equipped autoclave is shown in Fig. 3.

In the HPHT experiments, a calcium chloride solution was heated to $120{ }^{\circ} \mathrm{C}$ and a pressure of 10 bar was applied by loading nitrogen to the autoclave. The reaction was started by the addition of a $\mathrm{NaHCO}_{3}$ solution leading to final concentrations of $\mathrm{Ca}^{2+}$ and $\mathrm{HCO}_{3}{ }^{-}$of $5 \mathrm{mmol} / \mathrm{L}$. The concentration of $5 \mathrm{mmol}$ was chosen because a similar concentration was found for hydrogen carbonate ions in fluids from geothermal power plants in Southern Germany (Molasse Basin, Wanner et al. 2017) experiencing severe calcite scaling problems. The inhibitor was always added to the sodium bicarbonate solution before the injection into the autoclave to avoid preliminary interactions between inhibitor and metal ions. An initial pH value between 9.48 and 10.12 was measured at HPHT conditions (see Table 1) and a high calcite oversaturation represented by a calculated saturation index of $\mathrm{SI}=2.79\left(\right.$ at $120^{\circ} \mathrm{C}$ and $\mathrm{pH}=10$ ) was reached. The comparatively high oversaturation of calcite ensures short reaction times of the precipitation 


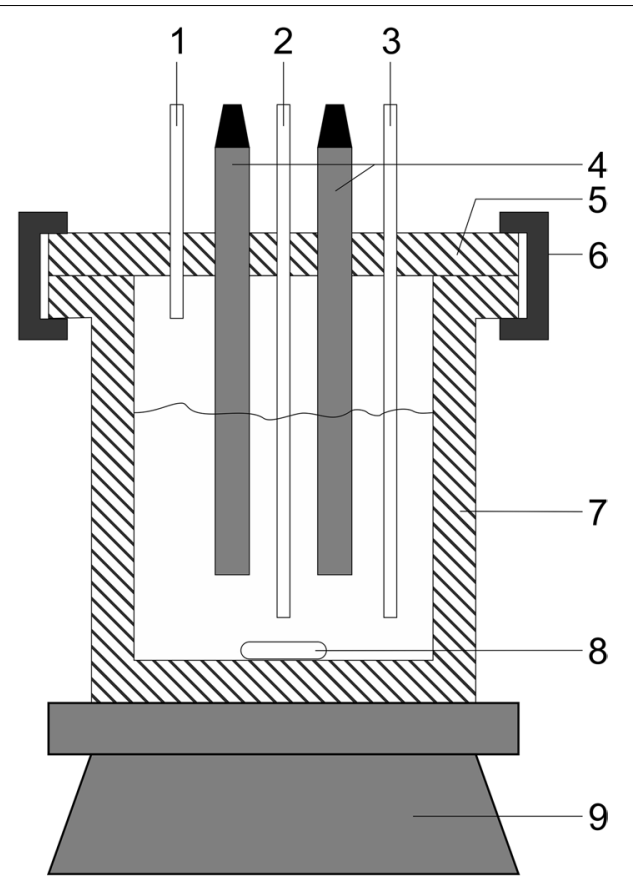

Fig. 3 Schematic of the HPHT autoclave installation. 1-lead-in for gas loading/unloading and pressure release, 2-lead-in for thermocouple (temperature control), 3-lead-in for liquid injection, 4-HPHT probes, 5-autoclave lid with threaded bores, 6-clamping, 7—-stainless steel autoclave, 8-magnetic stirrer, 9heating/stirring control unit

Table 1 Experiments with their measured initial and final pH-values

\begin{tabular}{lcccc}
\hline $\begin{array}{l}\text { Measurement } \\
\text { conditions }\end{array}$ & $\begin{array}{l}\text { Inhibitor } \\
\text { concentration }(\mathbf{p p m})\end{array}$ & Initial pH-value & Final pH-value & $\Delta \mathbf{p H}$ \\
\hline HPHT & 0 & 10.00 & 8.47 & -1.53 \\
HPHT & 10 & 10.12 & 9.21 & -0.91 \\
HPHT & 25 & 9.95 & 9.29 & -0.66 \\
HPHT & 50 & 10.10 & 9.57 & -0.53 \\
HPHT & 100 & 9.48 & 9.03 & -0.45 \\
Ambient & 0 & 8.96 & 7.73 & -1.23 \\
Ambient & 2 & 9.11 & 8.77 & -0.34 \\
Ambient & 5 & 8.93 & 8.82 & -0.11 \\
Ambient & 10 & 9.14 & 9.05 & -0.09 \\
\hline
\end{tabular}

experiments. The decrease in $\mathrm{pH}$-value and electrical conductivity was monitored over a reaction time of $4 \mathrm{~h}$.

The experiments at ambient conditions were carried out at normal pressure and $30{ }^{\circ} \mathrm{C}$. In order to reach a similar oversaturation compared to the HPHT experiments, the starting pH-value was increased by the addition of $100 \mu \mathrm{L}$ of $\mathrm{NaOH}$ solutions with a concentration of $1 \mathrm{~mol} / \mathrm{L}$. This addition lead to an increase in $\mathrm{pH}$ reaching initial $\mathrm{pH}$ values between 8.93 and 9.14 (calculated $\mathrm{SI}=2.13$ at $30{ }^{\circ} \mathrm{C}$ and $\mathrm{pH}=9)$ and also marked the starting point of the precipitation experiments at ambient conditions. Saturation indices were calculated by using the program PHREEQC (phreeqc.dat data base). $\Delta \mathrm{pH}$-values were calculated by subtraction of the maximum 
$\mathrm{pH}$ value from the $\mathrm{pH}$ value at the end of the experiment. The MIC was determined as the concentration of inhibitor that was necessary to reduce the change in $\mathrm{pH}$ to at least half the value obtained without inhibitor within the 4-h reaction time (Zotzmann and Regenspurg 2015). The indication of concentrations in ppm refers to the volume ratio $\mu \mathrm{L} / \mathrm{L}$.

Thermal/hydrolytic stability was investigated in a long-term experiment of the scaling inhibitor diluted 1:1 with water in the laboratory autoclave (conditions: $\left.T=150{ }^{\circ} \mathrm{C}, p=10 \mathrm{bar}\right)$. The experiment was carried out over 4 weeks and sampled after certain time intervals $(1,2,7,14$, and 28 days). Samples were analysed by Fourier Transform-infrared spectrometry (FTIR) and liquid chromatography.

For FTIR, an attenuated total reflection system was used (ATR-FTIR, Tensor 27, Bruker GmbH, Bremen, Germany) that was equipped with a HPHT measuring cell. The temperature of the measuring cell was regulated with a water thermostat. IR spectra at elevated temperatures were recorded after the thermostat showed a constant temperature over $1 \mathrm{~min}$. During a measurement, 32 scans were taken in a spectral range from 3400 to $600 \mathrm{~cm}^{-1}$ and with a resolution of $4 \mathrm{~cm}^{-1}$.

Measurements of the molecular weight distribution of the polymeric inhibitors were realized with size exclusion liquid chromatography and organic carbon detection (LC-OCD, see Huber et al. 2011 and Huber and Frimmel 1996). For the chromatography, a phosphate buffer ( $\mathrm{pH}$ 6.85) was used as mobile phase with a flow of $1.1 \mathrm{~mL} / \mathrm{min}$. The sample passed a $0.45 \mu \mathrm{m}$ membrane syringe filter before entering the chromatographic column $(250 \mathrm{~mm} \times 20 \mathrm{~mm}$, TSK HW 50S, Toso, Japan). After chromatographic separation, the organic compound fractions were characterized by UV detection and quantification by IR detection of released $\mathrm{CO}_{2}$ after UV photooxidation in a thin-film reactor.

Solid samples (precipitates) were analysed by scanning electron microscopy (SEM) after gold vaporization at a beam current acceleration of $20 \mathrm{kV}$ with an adjusted maximum aperture of $120 \mu \mathrm{m}$.

The applied calcite scale inhibitors were aqueous solutions of polycarboxylates consisting of polyacrylates with an addition of amino acids (Niederrhein Chemie $\mathrm{GmbH}$, Kevelaer, Germany). The exact composition of the inhibitors is confidential. Three different inhibitors varying in $\mathrm{pH}$-value and the content of polycarboxylate were subjected to compatibility tests. One inhibitor that was compatible with saline fluids was chosen for effectivity measurements. This inhibitor (NC48.1) consisted of an aqueous solution with a content of polycarboxylates of $>30 \%$ and a $\mathrm{pH}$-value of 7 .

\section{Results and discussion} Inhibitor compatibility

The compatibility of the inhibitors with geothermal fluids of high salinity was checked by adding them to $\mathrm{NaCl}$ solutions of different ionic strength according to the natural fluids that can be found in low enthalpy reservoirs. All inhibitors showed compatibility with solutions of concentrations of $0.1,2$, and $5 \mathrm{~mol} / \mathrm{L} \mathrm{NaCl}$. Only one inhibitor showed flocculation in the solution with the highest salinity and was therefore incompatible with geothermal fluids of high salinity. 


\section{Inhibitor effectivity}

The challenge of measuring effectivities of scaling inhibitors under HPHT conditions is to find a suitable method of monitoring the change of a physico-chemical value during precipitation. Several analytical methods were investigated in order to evaluate their potential to detect scaling inhibition. The ATR-FTIR allows measurements at HPHT conditions. However, IR measurements of the inhibitors in water and in solutions of $\mathrm{BaCl}_{2}$ and $\mathrm{Na}_{2} \mathrm{SO}_{4}$ showed no interpretable differences in the vibration bands. Furthermore, in order to detect the inhibitors vibration bands, the IR measurements had to be carried out at a much higher concentration of inhibitor than expected in practical effectivity tests.

The precipitation of minerals from a solution changes the ion concentration and thus the sonic velocity and the electrical conductivity within the solution. The change of these physical quantities during scaling was investigated by applying an ultrasound probe and an electric conductivity probe in precipitation experiments. Only a very slight dependence of the sonic velocity from changes in ion concentrations could be determined that would make the monitoring of precipitation processes in geothermal dimensions impractical. In contrast, its dependence on temperature changes is much higher and would require a constancy of temperature during the experiments that is very difficult to achieve. On the other hand, the change in electrical conductivity could be measured during precipitation experiments applying an HPHT conductivity sensor. However, a slight but distinct decrease in electrical conductivity was observed only in fluids of low salinity. Highly saline fluids maintain their high electrical conductivity during scaling processes. Therefore, measurements of the electrical conductivity are not suitable to monitor scaling processes in geothermal brines.

During the precipitation of calcite, carbonate ions are removed from the solution and the carbonic acid-carbonate equilibrium (Eq. 1) is imbalanced. To reinstate the chemical equilibrium, carbonate ions are generated by the dissociation of carbonic acid which also releases protons to the solution (according to Eq. 2).

$$
\begin{aligned}
& \mathrm{H}_{2} \mathrm{CO}_{3}+2 \mathrm{H}_{2} \mathrm{O} \rightleftarrows \mathrm{HCO}_{3}^{-}+\mathrm{H}_{3} \mathrm{O}^{+}+\mathrm{H}_{2} \mathrm{O} \rightleftarrows \mathrm{CO}_{3}^{2-}+2 \mathrm{H}_{3} \mathrm{O}^{+} \\
& \mathrm{HCO}_{3}^{-}+\mathrm{H}_{2} \mathrm{O} \stackrel{+\mathrm{Ca}^{2+}}{\rightarrow} \mathrm{CaCO}_{3}(\mathrm{~s})+\mathrm{H}_{3} \mathrm{O}^{+} .
\end{aligned}
$$

The calcite scaling therefore can be quantified by measuring the decrease in $\mathrm{pH}$ value (Zhang et al. 2012; Sousa et al. 2016). The measurement of the $\mathrm{pH}$-values was realized by applying a HPHT solid phase $\mathrm{pH}$-sensor. The experiments with their measured initial and final (after $4 \mathrm{~h}$ reaction time) $\mathrm{pH}$-values are summarized in Table 1. The extent of precipitation after reaching the equilibrium is represented by the difference in $\mathrm{pH}(\Delta \mathrm{pH})$. HPHT experiments were carried out with $0,10,25,50$, and $100 \mathrm{ppm}$ inhibitor. The decrease of the $\mathrm{pH}$ value due to calcite precipitation was highest when no inhibitor was added $(\Delta \mathrm{pH}=-1.53)$. The value of $\Delta \mathrm{pH}$ increased with increasing concentration of inhibitor indicating that calcite precipitation was indeed inhibited. However, a $\Delta \mathrm{pH}$ of -0.45 at an inhibitor concentration of $100 \mathrm{ppm}$ showed that the inhibition was always incomplete. Within the HPHT series, the MIC was determined as 25 ppm (Zotzmann and Regenspurg 2015). It became evident that very 

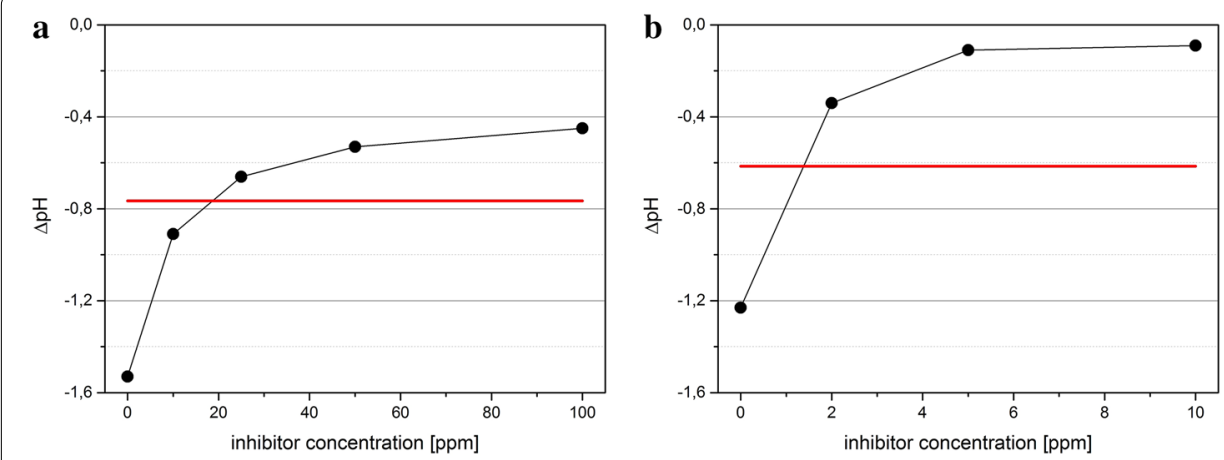

Fig. 4 Decrease of $\mathrm{pH}(\triangle \mathrm{pH})$ during precipitation in dependence of the inhibitor concentration in a HPHT experiments and $\mathbf{b}$ experiments at ambient conditions (from Zotzmann and Regenspurg 2015). The red line marks the $\Delta \mathrm{pH}$ of half the value obtained without inhibitor so that the first data point above that line represents the MIC

high concentrations of the investigated inhibitor are required to achieve an inhibitory effect. The percentage effectivity at the highest tested dosage of $100 \mathrm{ppm}$ is $70 \%$. The considerable decrease of the $\mathrm{pH}$-value at inhibitor concentrations even higher than $25 \mathrm{ppm}$ indicates an incomplete inhibition of calcite scaling. After the experiments, precipitations could be observed that are potentially damaging for geothermal installations. The inhibitor effectivity tests at ambient conditions were carried out applying inhibitor concentrations of $0,2,5$, and $10 \mathrm{ppm}$, whereas the MIC was determined as 2 ppm (Zotzmann and Regenspurg 2015). At an inhibitor concentration of 10 ppm, no precipitations could be observed. Apparently, under ambient conditions, the efficiency of the inhibitor is excellent being lower by more than one order of magnitude compared to the HPHT experiments. This difference confirms the dependence of the inhibitory effect from the p,T-conditions and the necessity to determine MIC values under HPHT conditions, when comparing the efficiency of scale inhibitors intended for geothermal application. Figure 4 shows the dependence of $\Delta \mathrm{pH}$ from the inhibitor concentration.

The effectivity of scaling inhibition can also be analysed after termination of the precipitation experiments by measuring the remaining concentration of the ions in solution after the precipitation was filtered off or by weighing the washed and dried solids after filtration. However, these off-line methods bear the disadvantage of representing measurements after the reaction mixture was allowed to reach ambient $\mathrm{p}, \mathrm{T}$ conditions. Besides the different conditions during the reaction and the analysis, also reaction quenching and necessary sample preparation steps potentially influence the analytical results.

The precipitations from the HPHT experiments were investigated by SEM. A dependence can be seen of shape and size of the calcite crystals from the concentration of the inhibitor. Figure 5 shows SEM pictures from the calcite scales in 3270fold magnification. With increasing concentration of inhibitor the size of the calcite crystals decreases. Furthermore, the cubic shape of the crystals deteriorates showing more and more defects on edges and corners with increasing inhibitor concentration. This result supports the assumption that the inhibition mechanism is based on the 


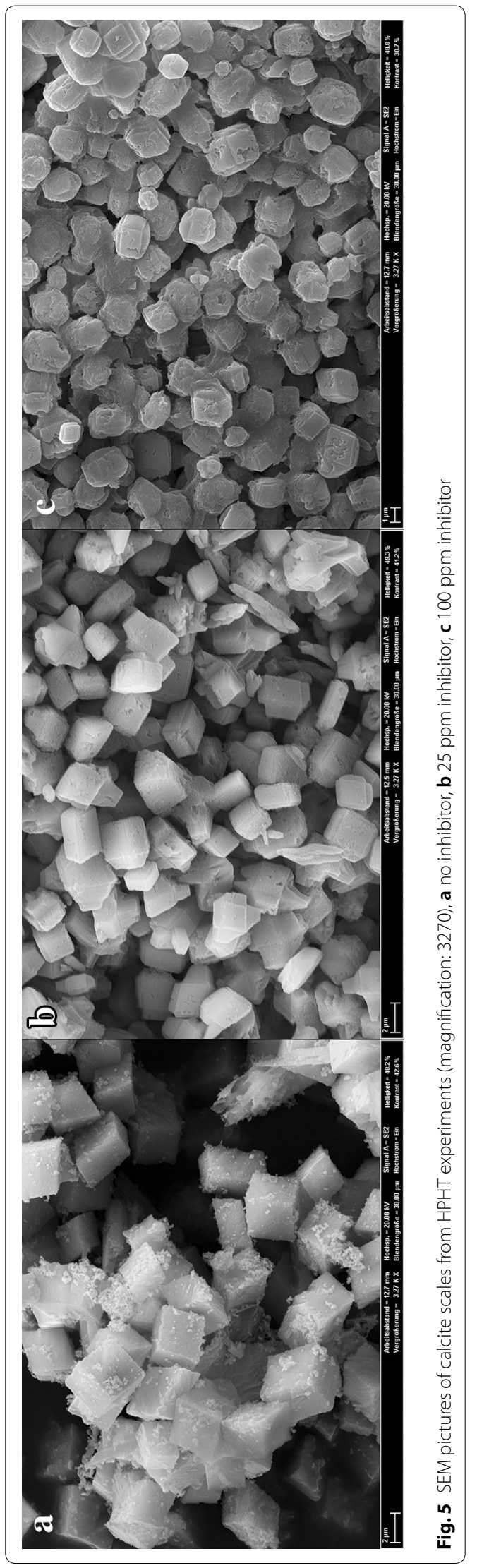




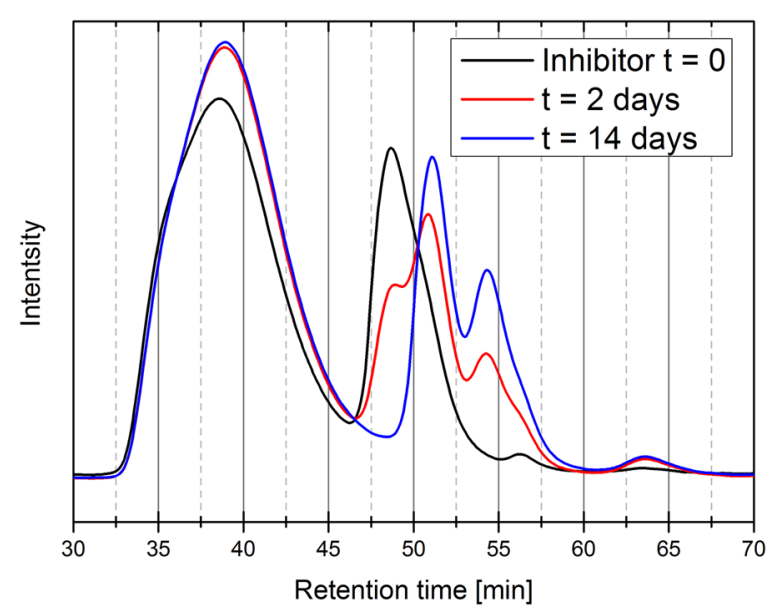

Fig. 6 Chromatograms from LC-OCD measurements indicating the molecular weight distribution of the scaling inhibitor during the long-term degradation experiment

threshold effect. The inhibitor molecules deactivate growth centres on the microcrystals in solution as well as on the surface of the precipitated calcite crystals that leads to a perturbation and finally to an inhibition of the crystal growth.

\section{Inhibitor Stability}

The thermal and hydrolytic stability of the inhibitor needs to be investigated. It is expected that polymer-based scaling inhibitors will be subject to hydrolytic and thermal degradation when exposed to HPHT conditions. The time frame of this degradation (and simultaneously the duration of the inhibition performance) is of particular interest for the application of environmental friendly inhibitors which are considered to be degradable. The desired lifetime of a degradable scaling inhibitor is stability over a few weeks or months and a complete degradation within 1 year. In two experiments at HPHT conditions, the short-term stability of polycarboxylate-based calcite scaling inhibitor was investigated. In a HPHT measuring cell of an ATR-FTIR spectrometer, a solution of the inhibitor was stepwise heated up to $95{ }^{\circ} \mathrm{C}$. After each $10{ }^{\circ} \mathrm{C}$ step an IR spectrum was recorded but no band shifting detected. Within this short experiment, the inhibitor showed no instant degradation at elevated temperatures. In a 4-week experiment under HPHT conditions, in a laboratory autoclave, the inhibitor solution was sampled in certain time intervals and investigated via IR measurements. No significant degradation of the inhibitor was detected by IR measurements of the long-term stability experiment. However, a considerable discolouration of the solution indicated some degradation apparently being not detectable by the IR measurements. A size exclusion chromatography with organic-carbon detection was employed to monitor the molecular weight distribution of the polymeric inhibitor during the experiment (see Fig. 6). No difference was observed between the chromatograms after 14 days and 28 days of experiment time so that the latter one is not shown.

The molecular weight distribution of the inhibitor at $t=0$ showed several components of different molecular weights. Components exhibiting a short retention time have a higher molecular weight than components with a long retention time. The two 
main components of the inhibitor were observed at retention times of 39 and $48.5 \mathrm{~min}$, respectively. After 2 weeks, the second component completely degraded resulting in two new species with lower molecular weight exhibiting retention times of 51 and $54 \mathrm{~min}$. It can be concluded that the inhibitor consisted of several components of different chemical composition. One of the main components of the inhibitor with the higher molecular weight is stable over 2 weeks at HPHT conditions while a second component with a lower molecular weight degrades over that time period.

Due to the long period over 2 weeks, however, this degradation can hardly be responsible for the considerable decrease in inhibitor efficiency under HPHT conditions in our short-term experiments. Instead, mineral formation and the inhibition mechanism are strongly temperature-dependent and substantiate a changing inhibition efficiency at elevated temperatures. For instance, the lower solubility of calcium carbonate at elevated temperatures has to be taken into account (Khormali et al. 2016).

\section{Conclusion}

With the sensor equipped autoclaves, a robust testing system was established being able to determine the efficiency of calcite scaling inhibitors under conditions prevailing in geothermal reservoirs. The measurement of $\mathrm{pH}$-values was proved to be a suitable method to detect calcite precipitation under HPHT conditions. Thus, evaluation and comparison of calcite scaling inhibitors for geothermal purposes in laboratory scale have been enabled. The results of the inhibition tests showed a decrease in the efficiency of the inhibitor at HPHT conditions compared with ambient conditions and thus demonstrate the requirement of HPHT tests. While the tested inhibitor has a high inhibiting efficiency under ambient conditions, under HPHT conditions an MIC of 25 ppm was determined. As for geothermal applications, this is considered a very high concentration so that the tested inhibitor most likely will not be a candidate to be used economically in a geothermal system. It was furthermore shown that the inhibitor partially degrades at reservoir conditions over time. The delayed degradation of the inhibitor avoids its persistence or accumulation in the reservoir.

\section{Abbreviations}

HPHT: high pressure, high temperature; ATR-FTIR: Fourier transform-infrared spectrometer with attenuated total reflection; LC-OCD: liquid chromatography with organic-carbon-detection; SEM: scanning electron microscopy.

\section{Authors' contributions}

JZ: experimental work and writing of the manuscript. AV: experimental work. SR: consulting and supervision. All authors read and approved the final manuscript.

Acknowledgements

The authors thank the "Kurt Schwabe Institut für Mess- und Sensortechnik Meinsberg" for the development of the HPHT sensors for application in the laboratory autoclaves. Furthermore, we thank Andrea Vieth-Hillebrand and Kristin Günther for recording LC-OCD chromatograms and Ilona Schäpan for providing SEM pictures.

Competing interests

The authors declare that they have no competing interests.

Availability of data and materials

Data will not be shared. Use in further work planned.

Consent for publication

Not applicable.

Ethics approval and consent to participate

Not applicable. 


\section{Funding}

Financial support from the German Federal Ministry of Economics and Technology (BMWi)/Federal Ministry of Environment (BMU) is gratefully acknowledged (Project "Thermoinhibitoren").

\section{Publisher's Note}

Springer Nature remains neutral with regard to jurisdictional claims in published maps and institutional affiliations.

Received: 11 December 2017 Accepted: 23 August 2018

Published online: 08 September 2018

\section{References}

Amro MA. Effect of scale and corrosion inhibitors on well productivity in reservoirs containing asphaltenes. J Petrol Sci Eng. 2005;46(4):243-52.

Baraka-Lokmane S, Sorbie KS, Poisson N, Lecocq P. Application of environmentally friendly scale inhibitors in carbonate Coreflooding experiments. In: International symposium of the society of core analysts,SCA2008-05, Abu Dhabi; 2008.

Bazin B, Kohler N, Zaitoun A. Some insights into the tube blocking test method to evaluate the efficiency of mineral scale inhibitors. In: SPE annual technical conference, SPE 96560, Dallas; 2005.

Boch R, Leis A, Haslinger E, Goldbrunner JE, Mittermayr F, Fröschl H, Hippler D, Dietzel M. Scale-fragment formation impairing geothermal energy production: interacting $\mathrm{H}_{2} \mathrm{~S}$ corrosion and $\mathrm{CaCO}_{3}$ crystal growth. Geother Energy. 2017:5:4.

Chaussemier M, Pourmohtasham E, Gelus D, Pécoul N, Perrot H, Lédion J, Cheap-Charpentier H, Horner O. State or art of natural inhibitors of calcium carbonate scaling. A review article. Desalination. 2015;356:47-55.

Choi DJ, You SJ, Kim JG. Development of an environmentally safe corrosion, scale, and microorganism inhibitor for open recirculating cooling systems. Mater Sci Eng. 2002;A335:228-36.

Collins IR, Stalker R, Graham GM. Sulphate removal for barium sulphate scale mitigation a deepwater subsea production system. In: 6th international symposium on oilfield scale, SPE 87465, Aberdeen; 2004.

Cooper KG, Hanlon LG, Smart GM, Talbot RE. The threshold scale inhibition phenomenon. Desalination. 1979:31:257-66.

Gallup DL. Production engineering in geothermal technology: a review. Geothermics. 2009;38(3):326-34

Graham GM, Boak LS, Sorbie KS. The influence of formation calcium and magnesium on the effectiveness of generically different barium sulphate oilfield scale inhibitors. SPE Prod Facil. 2003;18(1):28-44.

Graham AL, Boak LS, Neville A, Sorbie KS. How Minimum inhibitor concentration and sub-MIC concentrations affect bulk precipitation and surface scaling rates. SPE 93311. SPE Prod Oper. 2006;21:19-25.

Hasson D, Shemer H, Sher A. State of the art of friendly "green" scale control inhibitors. Ind Eng Chem Res. 2011;50:7601-6.

Huber SA, Frimmel FH. Size-exclusion-chromatography with organic carbon detection (LC-OCD): a fast and reliable method for the characterization of hydrophilic organic matter in natural waters. Vom Wasser. 1996;86:277-90.

Huber SA, Balz A, Abert M, Pronk W. Characterisation of aquatic humic and non-humic matter with size exclusion chromatography-organic carbon detection-organic nitrogen detection (LC-OCD-OND). Water Res. 2011;45:879-85.

Inches CE, Sorbie KS, Christophe C, Papirer L (2007) Thermal stability of selected green scale inhibitors. 18th internationa oil field chemistry symposium, Geilo; 2007.

Kavitha AL, Vasudevan T, Gurumallesh Prabu H. Evaluation of synthesized antiscalants for cooling water system application. Desalination. 2011;268:38-45.

Ketrane R, Saidani B, Gil O, Leleyter L, Baraud F. Efficiency of five scale inhibitors on calcium carbonate precipitation from hard water: effect of temperature and concentration. Desalination. 2009;249:1397-404.

Khormali A, Petrakov DG, Moein MJA. Experimental analysis of calcium carbonate scale formation and inhibition in waterflooding of carbonate reservoirs. J Petrol Sci Eng. 2016:147:843-50.

Lattemann S, Höpner T. Environmental impact and impact assessment of seawater desalination. Desalination. 2008;220:1-15.

Popov KI, Kovaleva NE, Rudakova GY, Kombarova SP, Larchenko VE. Recent state-of-the-art of biodegradable scale inhibitors for cooling-water treatment applications (review). Therm Eng. 2016:63(2):122-9.

Reddy MM, Hoch AR. Calcite crystal growth rate inhibition by polycarboxylic acids. J Coll Int Sci. 2001;235:365-70

Regenspurg S, Wiersberg T, Brandt W, Huenges E, Saadat A, Schmidt K, Zimmermann G. Geochemical properties of saline geothermal fluids from the in situ geothermal laboratory Groß Schönebeck (Germany). Chemie der Erde-Geochem. 2010;70:3-12

Sorbie KS, Laing N (2004) How scale inhibitors work: mechanisms of selected barium sulphate scale inhibitors across a wide temperature range. In: 6th international symposium on oilfield scale, SPE 87470, Aberdeen; 2004.

Sousa MFB, Signorelli F, Bertran CA. Fast evaluation of inhibitors for calcium carbonate scale based on pH continuous measurements in jar test at high salinity conditions. J Petrol Sci Eng. 2016;147:468-73.

Sullivan PJ, Young T, Carey J. Effectiveness of polymer phosphonate blends for inhibition of $\mathrm{CaCO}_{3}$ Scale. Ind Water Treat. 1996;26:39-44.

Tomaszewska B, Pajakk L. Dynamics of clogging processes in injection wells used to pump highly mineralized therma waters into the sandstone structures lying under the Polish Lowlands. Arch Environ Prot. 2012;38(3):105-17.

Topçu G, Çelik A, Baba A, Demir MM. Design of polymeric antiscalants based on functional vinyl monomers for (Fe, MG) silicates. Energy Fuels. 2017;31:8489-96.

Wanner C, Eichinger F, Jahrfeld T, Diamond LW. Causes of abundant calcite scaling in geothermal wells in the bavarian molasse basin, southern Germany. Geothermics. 2017;70:324-38. 
Zhang X, Wu W, Li D, Zhao G. A new evaluation method of scale inhibitors for controlling $\mathrm{CaCO}_{3}$ scale in reverse osmosis system based on pH measurement. Adv Mater Res. 2012;356-360:2146-52.

Zotzmann J, Regenspurg S. Evaluating the efficiency of scaling inhibitors in geothermal fluids at high pressures and high temperatures. In: Proceedings world geothermal congress, Melbourne; 2015.

Submit your manuscript to a SpringerOpen ${ }^{\circ}$ journal and benefit from:

- Convenient online submission

- Rigorous peer review

- Open access: articles freely available online

- High visibility within the field

- Retaining the copyright to your article

Submit your next manuscript at $\boldsymbol{\Delta}$ springeropen.com 